\title{
Behavior of Cobalt in Iron- and Steel-making Processes
}

\author{
Shin-ya KITAMURA, ${ }^{1)}$ Akira HASEGAWA, ${ }^{2)}$ Hiroshi NOGAMI, ${ }^{3)}$ Nobuhiro MARUOKA, ${ }^{\text {) }}$ Hideki KURIYAMA, ${ }^{4)}$ \\ Mizuo SAKAKIBARA, ${ }^{5)}$ Yuka YUKAWA ${ }^{5)}$ and Mitsuru SATO ${ }^{5}{ }^{\prime}$
}

1) Institute of Multidisciplinary Research for Advanced Materials, Tohoku University, 2-1-1 Katahira, Aoba-ku, Sendai $980-8577$ Japan. 2) Department of Quantum Science and Energy Engineering, Graduate School of Engineering, Tohoku University, 6-6-01-2, Aramaki-aza-aoba, Aoba-ku, Sendai 980-8579 Japan.

3) Department of Chemical Engineering, Ichinoseki National College of Technology, Takanashi, Hagisho, Ichinoseki $021-8511$

Japan. $\quad 4$ 4) Graduate School of Engineering, Tohoku University, 2-1-1 Katahira, Aoba-ku, Sendai 980-8577 Japan.

5) Nippon Steel Technoresearch Corporation, KSP A101, Sakado 3-2-1, Takatsu-ku, Kawasaki $213-0012$ Japan.

(Received on September 6, 2007; accepted on October 10, 2007)

\begin{abstract}
During the decommissioning phase of a nuclear reactor, most of the steel-reinforced concrete shielding around the pressure vessel is considered as low-level radioactive waste. It is very desirable to reduce the radioactivity of the low-level radioactive waste to below the clearance level. Normally, the radioactivity of steel after irradiation is found to be proportional to the cobalt content. In this study, for the production of low-activation steel, the mixing source and the partition behavior of cobalt in the iron- and steel-making processes are investigated. The results are summarized as follows: (1) the cobalt content in hot metal was found to be approximately $20 \mathrm{ppm}$, and the main source was serpentine. The ratio of the cobalt content to the iron content in the ore varied from 1.5 to $6.5 \mathrm{ppm}$, depending on the brand. In the charge materials for the BOF process and typical refractories, the cobalt content was negligible except for some ferroalloys. (2) By thermodynamic calculations, it can be deduced that the activity coefficient of $\mathrm{CoO}$ is very small in the slag.
\end{abstract}

KEY WORDS: nuclear reactor; clearance level; low-activation steel; cobalt; oxidation.

\section{Introduction}

During the decommissioning phase of a nuclear reactor, most of the steel-reinforced concrete shielding around the pressure vessel is considered as low-level radioactive waste. In terms of life-cycle cost reduction, it is very desirable to reduce the radioactivity of such low-level radioactive waste to a level below the clearance level. With the support of the Ministry of Economy, Trade and Industry, a project named "Low-activation Reinforced Concrete Design Methodology (LARC-DM)" has been undertaken in Japan. One of the objectives of this project is to develop low-activation steel for structural components.

In general, steel contains small amounts of $\mathrm{Co}, \mathrm{Ni}, \mathrm{Nb}$, $\mathrm{Zn}$, and $\mathrm{Sn}$ that transform into ${ }^{60} \mathrm{Co},{ }^{59} \mathrm{Ni}$ or ${ }^{63} \mathrm{Ni},{ }^{94} \mathrm{Nb}$, ${ }^{65} \mathrm{Zn}$, and ${ }^{125} \mathrm{Sb}$, respectively, by thermal-neutron irradiation. Among these target elements, the radioactivity of steel after irradiation was found to be proportional to the cobalt content. ${ }^{1)}$ According to a study on the cobalt content in commercial steel bars, it was found to vary widely from 10 to $140 \mathrm{ppm}$ and the average value was $66 \mathrm{ppm} .{ }^{1)}$ Based on these results, in this project, the target of cobalt content in steel bars is set to the following three levels: (1) less than $30 \mathrm{ppm},(2)$ less than $10 \mathrm{ppm}$, and (3) less than $3 \mathrm{ppm}$.

To produce low-activation steel, it is important to identify the source of cobalt and to determine its behavior in iron- and steel-making processes. According to the previous research, ${ }^{1)}$ the main source of Co can be considered to be Ni-containing scrap. Therefore, the main rout to produce low activation steel would be the BF-BOF process without commercial scrap. In this study, the mixing source for cobalt in iron- and steel-making processes is clarified by the analysis of the cobalt content in various charged materials of $\mathrm{BF}$ and $\mathrm{BOF}$ processes, and the partition behavior between slag and metal are discussed.

\section{Source of Cobalt}

The cobalt content in various raw materials of the BF and BOF processes was analyzed. The following materials were sampled from Kimitsu Works, Nippon Steel Corporation: (1) sintered ore, lumpy iron ores (3 brands), pellets (3 brands), silica stone, serpentine, lumpy coke, powder coal, and dolomite as charge materials to the BF: (2) powder ore (7 brands) and lime stone supplied as charged material to the sintering plant; (3) coals (3 brands) as charged materials to the coke oven; and (4) burnt lime, fluorspar, and burnt dolomite as charged materials to the BOF. The cobalt content was analyzed by using inductively coupled plasma mass spectrometry (Seiko Instruments, SPQ 9000).

The composition of hot metal and slag include cobalt is shown in Tables 1 and 2. The cobalt content in the hot metal was approximately $20 \mathrm{ppm}$ and was distributed between slag and metal phases. The results of the analysis of the raw materials are shown in Table 3; here, PO, LO, PL, and CL indicate the brands of the powder ore, lumpy ore, 
Table 1. Chemical composition of hot metal (mass\%).

\begin{tabular}{|c|c|c|c|c|}
\hline $\mathrm{C}$ & $\mathrm{Si}$ & $\mathrm{Mn}$ & $\mathrm{S}$ & $\mathrm{Co}$ \\
\hline 4.83 & 0.23 & 0.12 & 0.027 & 0.0020 \\
\hline
\end{tabular}

Table 2. Chemical composition of slag (mass $\%$ ).

\begin{tabular}{|c|c|c|c|c|}
\hline $\mathrm{CaO}$ & $\mathrm{SiO}_{2}$ & $\mathrm{Al}_{2} \mathrm{O}_{3}$ & $\mathrm{MgO}$ & $\mathrm{CoO}$ \\
\hline 43.7 & 34.6 & 14.5 & 5.5 & 0.00064 \\
\hline
\end{tabular}

Table 3. Cobalt content in charge materials (mass $\%$ ).

\begin{tabular}{|c|c|c|c|}
\hline & & & Co \\
\hline \multirow{12}{*}{$\begin{array}{l}\text { Charged Materials } \\
\text { for } B F\end{array}$} & \multicolumn{2}{|l|}{ Sintered ore } & 0.0006 \\
\hline & \multirow{3}{*}{ Lumpy ore } & LO-a & 0.0004 \\
\hline & & LO-b & 0.0002 \\
\hline & & LO-c & 0.0001 \\
\hline & \multirow{3}{*}{ Pellets } & PL-a & 0.0002 \\
\hline & & PL-b & 0.0007 \\
\hline & & PL-c & 0.0008 \\
\hline & \multirow{3}{*}{ Flux } & Silica stone & 0.0028 \\
\hline & & Serpentine & 0.0075 \\
\hline & & Dolomite & $<0.001$ \\
\hline & \multicolumn{2}{|l|}{ Lumpy coke } & 0.0003 \\
\hline & \multicolumn{2}{|l|}{ Powder coal } & $<0.0001$ \\
\hline \multirow{8}{*}{$\begin{array}{l}\text { Charged Materials } \\
\text { for Sintering }\end{array}$} & \multirow{7}{*}{ Powder ore } & PO-a & 0.0003 \\
\hline & & PO-b & 0.0003 \\
\hline & & PO-c & 0.0004 \\
\hline & & PO-d & 0.0002 \\
\hline & & PO-e & 0.0002 \\
\hline & & PO-f & 0.0004 \\
\hline & & PO-g & 0.0002 \\
\hline & Flux & Lime stone & $<0.0001$ \\
\hline \multirow{3}{*}{$\begin{array}{l}\text { Charged Materials } \\
\text { for Coking }\end{array}$} & \multirow{3}{*}{ Powder coal } & CL-a & $<0.0001$ \\
\hline & & CL-b & $<0.0001$ \\
\hline & & CL-c & $<0.0001$ \\
\hline \multirow{3}{*}{$\begin{array}{l}\text { Charged Materials } \\
\text { for BOF }\end{array}$} & \multirow{3}{*}{ Flux } & Burnt lime & $<0.001$ \\
\hline & & Burnt dolomite & $<0.001$ \\
\hline & & Fluorspar & $<0.001$ \\
\hline
\end{tabular}

pellets, and coal, respectively. The cobalt content was found to be high in serpentine and silica sand. In the iron ore, the ratio of cobalt content to iron content varied from 1.5 to $6.5 \mathrm{ppm}$ depending on the brand. The mass balances of cobalt in the iron-making process are summarized in Fig. 1. Serpentine was identified to be the main source, and it was followed by the ore and coke; however, the source for a significant percentage could not be identified.

On the other hand, in the charged materials for the BOF process, the cobalt content was found to be negligible, as shown in Table 3.

The cobalt content in the refractory was investigated. Among the various types of refractories in the BF-BOF process the clay used to plug the tap hole of the BF, the lining bricks of the BOF, the monolithic lining materials of the ladle, and the immersion nozzle of the continuous casting were selected as their high erosion rate. As shown in Table 4 , the cobalt content in the refractory was negligible.

The cobalt content in the alloying materials is shown in Table 5. A high content of cobalt was found in ferronickel, high-carbon ferrochromium and high-carbon ferromanganese. Therefore, the addition of the low-cobalt-containing alloy is considered to be imperative for producing lowcobalt-containing steel.
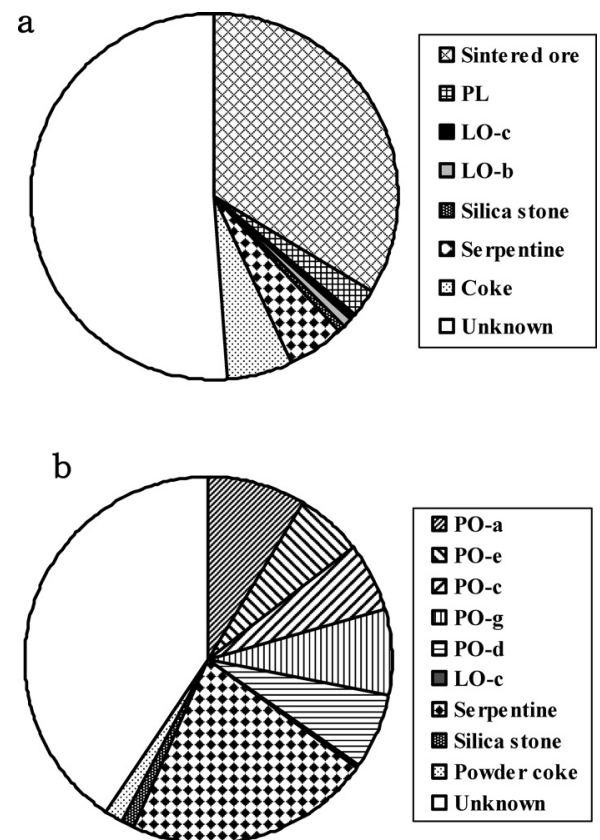

Fig. 1. Mass balance of cobalt in BF (a) and sintering process (b).

Table 4. Cobalt content in refractories (mass $\%$ ).

\begin{tabular}{|l|c|}
\hline \multicolumn{1}{|c|}{ Refractory } & Co \\
\hline Clay to Plug Tap Hole of BF & $<0.001$ \\
\hline MgO-C Brick of BOF & $<0.001$ \\
\hline Monolithic Lining of Ladle & $<0.001$ \\
\hline Immersion Nozzle of CC & $<0.001$ \\
\hline
\end{tabular}

Table 5. Cobalt content in alloying materials (mass\%).

\begin{tabular}{|l|c|}
\hline \multicolumn{1}{|c|}{ Alloy } & Co \\
\hline High Carbon Ferromanganese & $\mathbf{0 . 0 2 1}$ \\
\hline Low Carbon Ferromanganese & $\mathbf{0 . 0 0 8}$ \\
\hline Ferrosilicon & $\mathbf{0 . 0 0 2}$ \\
\hline Ferronickel & $\mathbf{0 . 4 1}$ \\
\hline Nickel & $\mathbf{0 . 0 0 3}$ \\
\hline Low Carbon Ferromolybdenum & $\mathbf{0 . 0 0 4}$ \\
\hline High Carbon Ferrochromium & $\mathbf{0 . 0 4 2}$ \\
\hline Aluminum & $\mathbf{0 . 0 0 1}$ \\
\hline
\end{tabular}

\section{Experiment to Produce Low-cobalt-containing Hot Metal}

Laboratory experiments were carried out to produce lowcobalt-containing hot metal by selecting raw materials. The mixing conditions and the cobalt content in the metal after the experiments are summarized in Table 6. In the first run, the same charging ratio used in the Kimitsu BF process was adopted, except for the pellets and the other recycling materials. In the second run, serpentine-one of the main sources of cobalt - was replaced with dolomite. In the third run, only low-cobalt-content ore was used (PO-d). The powder materials were mixed in appropriate ratios and pressed to form tablets. These tablets were heated at $1723 \mathrm{~K}$ for $12 \mathrm{~h}$ in a $\mathrm{CO}$ atmosphere by using graphite crucibles.

As shown in Table 5, the cobalt content in the hot metal was found to be $10 \mathrm{ppm}$ in runs 2 and 3 . In this run, as the main sources were ore and coke, this content would be the 
Table 6. Mixing conditions and results of the experiments performed to produce low-cobalt-containing hot metal.

\begin{tabular}{|c|c|c|c|c|c|}
\hline & & Run & 1 & 2 & 3 \\
\hline \multirow{12}{*}{$\begin{array}{l}\text { Mixing } \\
\text { conditions } \\
(\text { mass \%) }\end{array}$} & \multirow{7}{*}{$\begin{array}{l}\text { Ore } \\
\text { brand }\end{array}$} & PO-a & 10.5 & 10.5 & $\mathbf{0}$ \\
\hline & & PO-e & 10.5 & 10.5 & $\mathbf{0}$ \\
\hline & & PO-c & 5.6 & 5.6 & 0 \\
\hline & & PO-g & 14 & 14 & $\mathbf{0}$ \\
\hline & & PO-d & 11.9 & 11.9 & 61.65 \\
\hline & & LO-b & 4.8 & 4.8 & $\mathbf{0}$ \\
\hline & & LO-c & 7.8 & 7.8 & 0 \\
\hline & \multicolumn{2}{|c|}{ Serpentine } & 1.7 & $\mathbf{0}$ & $\mathbf{0}$ \\
\hline & \multicolumn{2}{|c|}{ Dolomite } & $\overline{0}$ & 3.5 & $\overline{3.5}$ \\
\hline & \multicolumn{2}{|c|}{ Silica stone } & 0.4 & 1.1 & 1.1 \\
\hline & \multicolumn{2}{|c|}{ Lime } & 9.7 & 8.5 & 8.5 \\
\hline & \multicolumn{2}{|l|}{ Coke } & 23.1 & 23.1 & 23.1 \\
\hline Results & \multicolumn{2}{|c|}{ Co (ppm) } & 18 & 10 & 10 \\
\hline
\end{tabular}

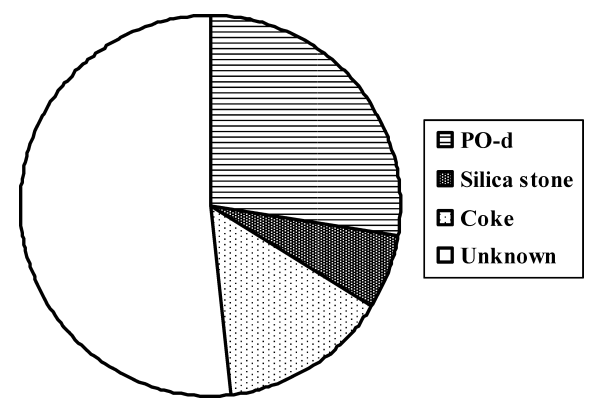

Fig. 2. Mass balance of cobalt in the experiment performed to produce low-cobalt-containing hot metal (run 3).

minimum value produced by the conventional BF process. The mass balance of cobalt in run 3 is shown in Fig. 2. Although the weights of input and output materials were measured precisely, the source for a significant percentage could not be identified again. It is very difficult to analyze the cobalt content of oxide materials in ppm level by ICP technique. The instrumental neutron activation analysis, in which $\gamma$-ray intensity is measured of each element which activated by neutron irradiation, will be carried out to clarify the mass balance.

\section{Experiment to Produce Low-cobalt-containing Steel}

The middle-scale experiments were conducted by using an induction furnace with a capacity of $500 \mathrm{~kg}$ to simulate the BOF operation. After the melting of the pig iron, oxygen gas was blown from top lance and Ar gas was injected from a porous brick installed at the bottom of the furnace. During the refining process, burnt lime was added to make slag, and iron ore and steel chips were added to control the bath temperature. After the refining, the molten steel was deoxidized by $\mathrm{Al}$, and $\mathrm{C}, \mathrm{Si}$, and $\mathrm{Mn}$ were added for the adjustment of the composition to that of a typical steel bar. In this experiment, in order to avoid cobalt input from alloying materials, high purity metals were used. The changes in the composition and temperature during the refining process are shown in Figs. 3 and 4, respectively. The cobalt content was almost the same during the refining process, although the carbon content and temperature changed. The mass balance of cobalt after alloying is shown in Fig. 5. The main source was found to be hot metal and steel chips. The

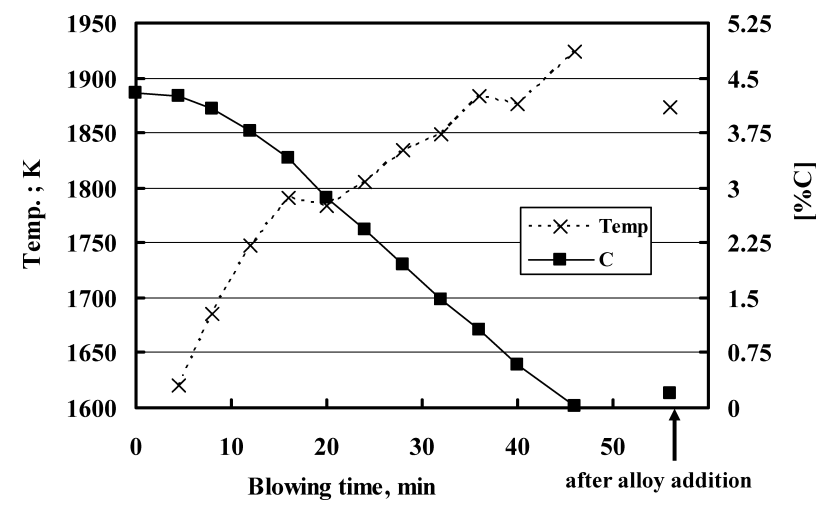

Fig. 3. Change in temperature and carbon content during the decarburization experiment.

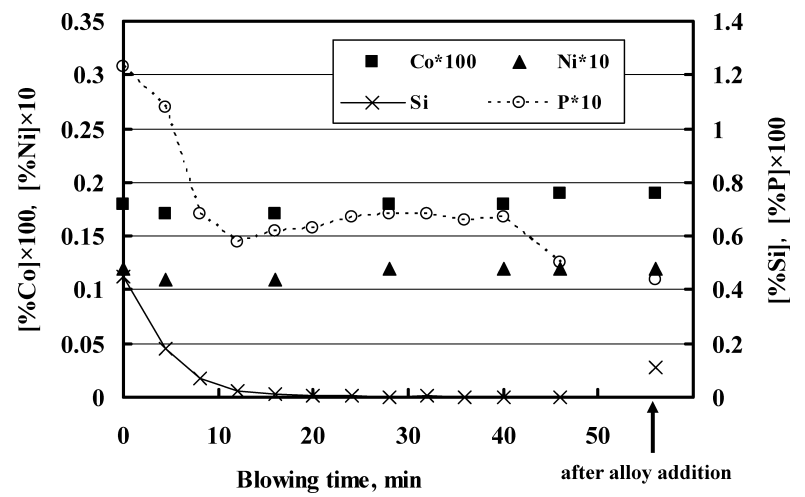

Fig. 4. Change in composition during the decarburization experiment.

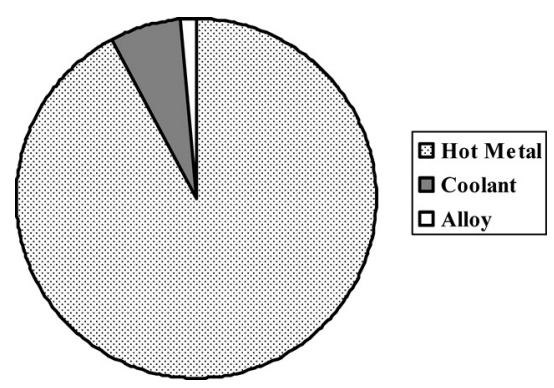

Fig. 5. Mass balance of cobalt in the decarburization experiment.

change in the slag composition and partition ratio of cobalt during refining are shown in Fig. 6. The partition ratio of cobalt between the slag and the metal was less than 0.5 . From this experiment, it can be concluded that the cobalt content does not increase in the BOF unless high-cobaltcontaining coolant or alloying materials are used.

\section{Measures to Produce Low-activation Steel}

From these results, the first target-less than $30 \mathrm{ppm}$ of cobalt - can be achieved by the conventional BF-BOF process for a BOF operation without using high-cobalt-containing scraps and alloys. Moreover, the second target-less than $10 \mathrm{ppm}$ - can be achieved if the selected materials are used in the BF process. In order to achieve the final target-less than $3 \mathrm{ppm}-\mathrm{a}$ conventional BF-BOF process would not be appropriate; hence, the development of novel technology is necessary. 


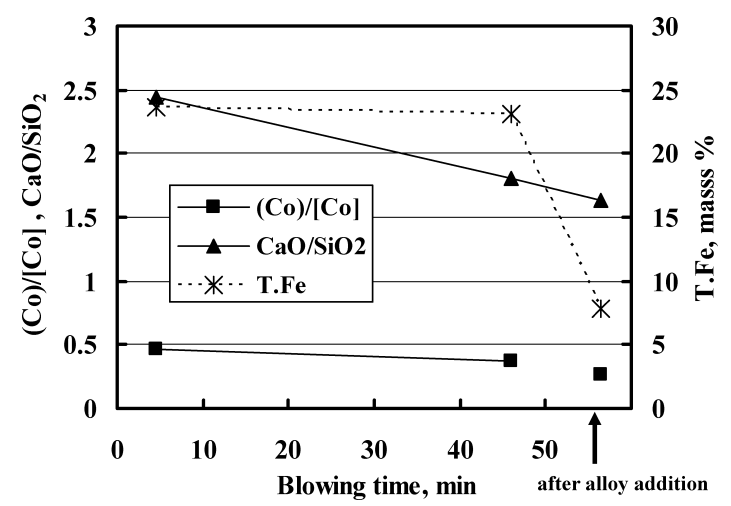

Fig. 6. Change in slag composition and partition ratio of cobalt during decarburization experiment.

\section{Discussion on Slag/Metal Partition of Cobalt}

The observed partition ratios for cobalt in a BF and BOF are compared with those of other elements. The general formula for the oxidation reaction of element [M] and its observed partition ratio are expressed in Eqs. (1) and (2), respectively.

$$
\begin{gathered}
2 / n[\mathrm{M}]+\mathrm{O}_{2}(\mathrm{~g})=2 / n \cdot\left(\mathrm{MO}_{n}\right) \\
L_{\mathrm{M}}=\left(\% \mathrm{MO}_{n}\right)^{2 / n} /[\% \mathrm{M}]^{2 / n} \ldots
\end{gathered}
$$

Equation (3) relates the equilibrium constant $\left(K_{\mathrm{M}}\right)$ and partition ratio $\left(L_{\mathrm{M}}\right)$.

$$
\begin{aligned}
K_{\mathrm{M}} & =a_{\mathrm{MO}_{n}}^{2 / n} /\left(a_{\mathrm{M}}^{2 / n} \times P_{\mathrm{O}_{2}}\right) \\
& =\left(\gamma_{\mathrm{MO}_{n}}^{2 / n} \times N_{\mathrm{MO}_{n}}^{2 / n}\right) /\left(f_{\mathrm{M}}^{2 / n} \times[\% \mathrm{M}]^{2 / n} \times P_{\mathrm{O}_{2}}\right) \\
& =L_{\mathrm{M}} \times\left(\gamma_{\mathrm{MnO}_{n}}^{2 / n} \times X_{\mathrm{MO}_{n}}^{2 / n}\right) /\left(f_{\mathrm{M}}^{2 / n} \times P_{\mathrm{O}_{2}}\right) \ldots \ldots . . .
\end{aligned}
$$

where $a_{\mathrm{MO}_{n}}$ and $a_{\mathrm{M}}$ represent the activities of $\mathrm{MO}_{n}$ and $\mathrm{M}$ in the slag and metal, respectively; $\gamma_{\mathrm{MO}}$, the activity coefficient of $\mathrm{MO}_{n}$ based on Raoult's law; $N_{\mathrm{MO}_{n}}$, the mole fraction of $\mathrm{MO}_{n} ; X_{\mathrm{MO}_{n}}$, the parameter that changes the unit from mass $\%$ to mole fraction; $f_{\mathrm{M}}$, the activity coefficient of $\mathrm{M}$ based on Henry's law on the basis of one mass \%; and $P_{\mathrm{O}_{2}}$, the oxygen potential.

The relationship between the apparent partition ratio defined in Eq. (4) and the equilibrium constant can be expressed as given in Eq. (5).

$$
\begin{aligned}
& L_{\mathrm{M}}^{\prime}=L_{\mathrm{M}} \cdot X_{\mathrm{MO}_{n}}^{2 / n} / f_{\mathrm{M}}^{2 / n} \cdots \\
& K_{\mathrm{M}} \cdot P_{\mathrm{O}_{2}}=L_{\mathrm{M}}^{\prime} \cdot \gamma_{\mathrm{MO}_{n}}^{2 / n}
\end{aligned}
$$

$K_{\mathrm{M}}$ can be calculated based on the standard free energy change, ${ }^{2)}$ and $f_{\mathrm{M}}$ is also calculated by using the interaction parameters for each element. ${ }^{2)}$

In the $\mathrm{BF}$, in order to calculate the oxygen potential, the oxidation reaction of silicon and the desulphurization reaction are considered. In the case of the oxidation reaction of silicon, the oxygen potential can be calculated by using Eq. (6).

$$
P_{\mathrm{O}_{2}}=L_{\mathrm{Si}} \times\left(\gamma_{\mathrm{SiO}_{2}} \times X_{\mathrm{SiO}_{2}}\right) /\left(f_{\mathrm{Si}} \times K_{\mathrm{Si}}\right)
$$

The activity coefficient of $\mathrm{SiO}_{2}$ in the BF slag is known ${ }^{3)}$ and it can be estimated to be equal to 0.2 . Using the ob-

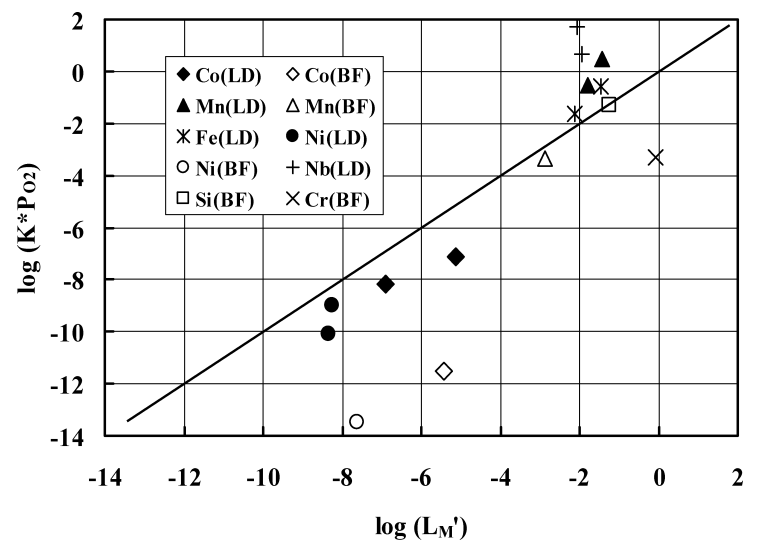

Fig. 7. Relation between $L_{\mathrm{M}}^{\prime}$ and $K \times P_{\mathrm{O}_{2}}$ for each oxidation reaction in the $\mathrm{BF}$ and decarburization experiment (LD).

served partition ratio of $\mathrm{Si}$, the oxygen potential is calculated as $10^{-13.8} \mathrm{~atm}$ at $1800 \mathrm{~K}$.

In the case of the desulphurization reaction, Eq. (7) is employed ${ }^{4)}$; in this equation, $C s$ represents the sulfide capacity, which can be calculated by using Eq. (8).

$$
\begin{aligned}
& \log (\% \mathrm{~S}) /[\% \mathrm{~S}]=\log C s-1 / 2 P_{\mathrm{O}_{2}}-7054 / T+2.224 \text {. } \\
& \log C s=1.35 \times\{1.79(\% \mathrm{CaO})+1.24(\% \mathrm{MnO})\} / \\
& \left\{1.66\left(\% \mathrm{SiO}_{2}\right)+0.33\left(\% \mathrm{Al}_{2} \mathrm{O}_{3}\right)\right\} \\
& -6911 / T-1.649 \text {. }
\end{aligned}
$$

By using the slag composition and the observed partition ratio for sulfur, the oxygen potential is calculated to be $10^{-13.8} \mathrm{~atm}$ at $1800 \mathrm{~K}$.

As there is good agreement between the calculated results obtained independently by using the two methods, the oxygen potential in the BF process is assumed to be $10^{-13.8} \mathrm{~atm}$.

In a BOF, to calculate the oxygen potential, the equilibrium relation of $\mathrm{C}-\mathrm{CO}$ is considered. From this reaction, the oxygen potential can be calculated by using Eq. (9).

$$
P_{\mathrm{O}_{2}}=1 /\left(a_{\mathrm{c}}^{2} \times K_{\mathrm{C}}\right)
$$

The activity of carbon is calculated by using the interaction parameters for each element.

The comparisons of the values of $\left(K_{\mathrm{M}} \cdot P_{\mathrm{O}_{2}}\right)$ and $L_{\mathrm{M}}^{\prime}$ for each of the reactions are shown in Fig. 7 for the BF and BOF. Here, $L_{\mathrm{M}}^{\prime}$ is considerably greater than $\left(K_{\mathrm{M}} \cdot P_{\mathrm{O}_{2}}\right)$ for the oxidation reactions of cobalt, particularly for the conditions in a BF. This implies that the activity coefficients of $\mathrm{CoO}$ are very small in comparison to those of $\mathrm{SiO}_{2}$ and $\mathrm{MnO}$. By using the following thermodynamic values, ${ }^{2)}$ the activity coefficient of $\mathrm{CoO}$ in the $\mathrm{BF}$ slag and decarburization slag were estimated as 0.001 and 0.09 , respectively.

$$
\begin{aligned}
& 2 \mathrm{Co}(\mathrm{l})+\mathrm{O}_{2}(\mathrm{~g})=2 \mathrm{CoO}(\mathrm{s}) \quad \Delta G^{\circ}=-497930+156.61 \times T \\
& \mathrm{Co}(\mathrm{l})=[\mathrm{Co}] \quad \Delta G^{\circ}=1000-38.74 \times T \ldots \ldots \ldots \ldots \ldots \ldots \ldots \ldots \ldots \ldots \ldots \ldots \ldots \ldots \ldots \ldots \ldots \ldots \ldots \ldots \ldots \ldots \ldots \\
&
\end{aligned}
$$

From the results of the equilibrium measurement between $\mathrm{Ni}-\mathrm{Fe}$ alloy, $\mathrm{Ni}-\mathrm{Cu}-\mathrm{Fe}$ alloy, and $\mathrm{FeO}-\mathrm{CaO}-\mathrm{MgO}-\mathrm{Al}_{2} \mathrm{O}_{3}-$ $\mathrm{SiO}_{2}$ system slag, ${ }^{5,6)}$ a value of approximately 0.02 was obtained as the cobalt partition ratio at approximately $1825 \mathrm{~K}$ under an oxygen potential of $10^{-9} \mathrm{~atm}$. From these results, 
the activity coefficient of $\mathrm{CoO}$ in the slag was estimated as approximately 2 , and this value was almost similar to the values of the other results in $\mathrm{Cu}-\mathrm{Fe}$ alloy and copper-refining slag. ${ }^{7)}$ Although the cobalt content in the metal and slag phases of the previous experiments were considerably higher, the partition ratio and activity coefficients are significantly different from those obtained in the present research. In some research of copper refining slag, the activity coefficient of $\mathrm{CoO}$ was formulated as a function of the cobalt content in the slag. ${ }^{8)}$ Although the activity coefficient of cobalt was estimated by this result, the error would not be negligible small as the contents in slag and metal are too low to obtain the precise values by chemical analysis. In this paper, a brief comparison of the partition ratio with the other oxide was discussed. The precise measurement of the activity coefficient of cobalt oxide in this system is a subject for future research.

Moreover, in future researches that aim to develop technology for lowering the cobalt content, it is important to determine the optimum slag conditions under which these activity coefficients are minimized.

\section{Conclusions}

In order to produce low-activation steel, the mixing sources of cobalt in iron- and steel-making processes were investigated and the following features were clarified.

(1) The cobalt content in hot metal was found to be approximately $20 \mathrm{ppm}$ and the main source was serpentine. The ratio of the cobalt content to the iron content in the ore varied from 1.5 to $6.5 \mathrm{ppm}$ depending on the brand. In the charge materials for the BOF process and typical refractories, the cobalt content was negligible except for some ferroalloys.

(2) Laboratory experiments were carried out to produce low-cobalt-containing hot metal by selecting raw materials. In these experiments, serpentine-one of the main sources of cobalt-was replaced with dolomite, and only lowcobalt-containing ore was selected. By these experiments, hot metal containing $10 \mathrm{ppm}$ of cobalt was obtained.

(3) From the middle-scale decarburization experiment performed to simulate the BOF operation, it can be concluded that the cobalt content does not increase in the BOF unless a high-cobalt-containing coolant or alloying materials are used.

(4) By thermodynamic calculations, it can be deduced that the activity coefficient of $\mathrm{CoO}$ are very small in the slag.

\section{Acknowledgements}

This work is supported by a Grant-in-Aid from the Innovative and Viable Nuclear Energy Technology (IVNET) development project of the Ministry of Economy, Trade and Industry, Japan. The authors are thankful to Nippon Steel Corporation, Kurosaki Harima Corporation, Nippon Steel and Sumikin Stainless Steel Corporation, and Nippon Denko Co., Ltd., for their support in sampling the materials.

\section{REFERENCES}

1) S. Kitamura, A. Hasegawa, M. Sakakibara, Y. Matsushima and M. Kinnno: Proceedings of AISTech 2007, Vol. 2, AIST, Warrendale, PA, (2007).

2) The Iron and Steel Institute of Japan: Tekkou Binnran 3rd Edition Part 1 Fundamentals, Maruzen, Tokyo, Japan, (1981), 20.

3) Verein Deutscher Eisenhuttenleute: Slag Atlas 2nd Edition, Verlag Stahleisen GmbH, Dusseldorf, Germany, (1995), 237.

4) A. S. Venkatradi and H. B. Bell: Trans. Metall. Soc. AIME, 207 (1969), 1110.

5) R. U. Pagador, M. Hino and K. Itagaki: Mater. Trans., 40 (1999), 225 .

6) H. M. Henao, M. Hino and K. Itagaki: Mater. Trans., 42 (2001), 1959.

7) K. C. Teague, D. R. Swinbourne and S. Jahanshahi: Metall. Mater. Trans. B, 32B (2001), 47.

8) B. Derin and O. Yücel: Scand. J. Metall., 31 (2002), 12. 